\title{
Cost Benefit Analysis of Prenatal Screening Test with Thai NIPT (Thai Non- Invasive Prenatal Test) for Down Syndrome in Developing Countries
}

\section{Oraluck $\mathrm{P}^{1}$, Boonsong $\mathrm{O}^{2}$, Wasun $\mathrm{C}^{3,4}$, Ammarin $\mathrm{T}^{1}$ and Panyu $\mathrm{P}^{5 *}$}

${ }^{1}$ Section for Clinical Epidemiology and Biostatistics, Faculty of Medicine, Ramathibodi Hospital, Mahidol University, Bangkok, Thailand ${ }^{2}$ Division of Endocrinology and Metabolism, Department of Medicine, Faculty of Medicine, Ramathibodi Hospital, Mahidol University, Bangkok, Thailand

${ }^{3}$ Virology Laboratory, Department of Pathology, Faculty of Medicine, Ramathibodi Hospital, Mahidol University, Bangkok, Thailand

${ }^{4}$ Center of Medical Genomics, Faculty of Medicine, Ramathibodi Hospital, Mahidol University, Bangkok, Thailand

${ }^{5}$ Maternal Fetal Medicine Unit, Department of Obstetrics and Gynecology, Faculty of Medicine, Ramathibodi Hospital, Mahidol University, Bangkok, Thailand

\section{Abstract}

Objective: The purpose of this study was to assess cost benefits of prenatal screening test for Down syndrome in developing countries (like Thailand) in order to inform OB/GYN clinical practice and medical/public health policy).

Methods: A decision tree model was developed to analyze cost-benefits of the two screening modalities versus conventional screening test as base case. The first screening modality was universal Thai NIPT (Thai Non-invasive Prenatal Test) and the second was contingent Thai NIPT. Input parameters related to clinical values and costs were obtained from both primary and secondary sources for Thai population. One-way analysis and probabilistic sensitivity analysis were performed to evaluate uncertainty surrounding model parameters.

Results: Based on the societal perspective, performing universal Thai NIPT and contingent Thai NIPT yielded differences of incremental benefit to incremental cost of $-4,472$ to $-3,784$ Thai Baht (-127.77 to -108.11 US $\$$ ) and 396 to 1,085 (11.31 to 31.00 US\$) when each was compared to conventional tests. The ratio of incremental benefit to incremental cost was 0.03 to 0.14 for universal Thai NIPT, respectively and thus cost was saved for contingent Thai NIPT.

Conclusion: Applying Thai NIPT as the first line of screening for Down syndrome might be cost beneficial if the price was around 4,047 to 4,795 Thai Baht or US\$ 115.63 to 137.00 per test. The contingent Down syndrome screening tests by offering the conventional tests first, then followed by Thai NIPT before performing the invasive screening test which seems to be a cost beneficial alternative approach.

Keywords: Trisomy of chromosome; Genetic disorder; Down syndrome

\section{Introduction}

Down syndrome is a genetic disorder mostly caused by the trisomy of chromosome 21 . The incidence in Thailand reported by the Ministry of Public Health was at 1:800 in 2008 [1]. In 2017, a population-based study in 3 southern provinces of Thailand reported the prevalence of 1.21 per 1,000 births during $2009-2013$. About $35 \%$ of these cases were diagnosed prenatally and later terminated [2]. Nowadays, patients with Down syndrome have no treatment or special health care system/insurance particularly in developing countries, thus they are at high risk for many associated abnormalities such as physical growth delays, characteristic facial features and mild-to-moderate intellectual disability.

Therefore, prenatal screening is one of the key strategies to reach the success of the antenatal care system which can avoid/reduce newborns with Down syndrome. The conventional prenatal screening tests include combined tests, triple test, quadruple test, integrated test and fully integrated test. Various models of the combination of these parameters have been developed and studied extensively. From our previous study, it was cost-beneficial to offer a Down syndrome prenatal screening to all pregnant women instead of doing amniocentesis on the basis of advanced maternal age alone [3]. Although the invasive procedures (chorionic villi sampling, amniocentesis and cordocetesis) are considered as the diagnostic tests, they are associated with fetal loss. Therefore, it would be better to have a high performance Down syndrome screening test with high sensitivity and low false positive rate. The cell free fetal DNA in maternal blood (Non-Invasive Prenatal Test; NIPT) is now available. The NIPT was introduced in $1997[4,5]$.
Currently, there are three methods of NIPT: Shortgun (genomewide) massively parallel sequencing (s-MPS), targeted (t-MPS) and single nucleotide polymorphism (SNP) methods. NIPT is much more accurate than the conventional tests. Previous study reported the Down syndrome detection rate of primary NIPT for all pregnant women is $6-14 \%$ higher than the conventional tests with 45 -fold FPR (false positive rate.) reduction from meta-analysis [6]. However, the NIPT is still more costly. In order to inform OB/GYN clinical practice and medical/public health policy, this study was conducted to assess the cost benefit of prenatal screening test for Down syndrome with non-invasive prenatal test in developing countries (like Thailand). The Thai NIPT, a not-for-profit service, has been established and wholly processed at Ramathibodi Hospital, Thailand by using s-MPS since 2014 [7].

\section{Methods}

This design was a cross-sectional study and cost benefit analysis,

${ }^{*}$ Corresponding author: Panyu Panburana, Maternal Fetal Medicine Unit Department of Obstetrics and Gynecology, Faculty of Medicine, Ramathibod Hospital, Mahidol University, 270 Rama VI Rd., Ratchathewi, Bangkok 10400 Thailand; Tel: 0818469343; E-mail: ppanburana@yahoo.com

Received August 21, 2017; Accepted September 05, 2017; Published September 12, 2017

Citation: Oraluck P, Boonsong O, Wasun C, Ammarin T, Panyu P (2017) Cost Benefit Analysis of Prenatal Screening Test with Thai NIPT (Thai Non-Invasive Prenatal Test) for Down Syndrome in Developing Countries. Health Care Current Reviews 5: 207. doi: 10.4172/2375-4273.1000207

Copyright: $\odot 2017$ Oraluck P, et al. This is an open-access article distributed unde the terms of the Creative Commons Attribution License, which permits unrestricted use, distribution, and reproduction in any medium, provided the original author and source are credited. 
Citation: Oraluck P, Boonsong O, Wasun C, Ammarin T, Panyu P (2017) Cost Benefit Analysis of Prenatal Screening Test with Thai NIPT (Thai NonInvasive Prenatal Test) for Down Syndrome in Developing Countries. Health Care Current Reviews 5: 207. doi: 10.4172/2375-4273.1000207

Page 2 of 7

which was conducted at antenatal care clinic, Ramathibodi Hospital, from $1^{\text {st }}$ January 2016 to $31^{\text {st }}$ December 2016. Pregnant women who underwent conventional tests and Thai NIPT during the study period were included in our study. A ratio of incremental benefit to incremental cost in societal perspective was estimated. Universal Thai NIPT was defined as to offer Thai NIPT as the first line test for all pregnant women while the contingent Thai NIPT policy referred to a two-stage screening strategy which consisted of the conventional test as a first line screening test and Thai NIPT was offered only if the risk shown by conventional test was more than the risk threshold. A decision tree model (Figure 1) was constructed to compare the cost benefit of two screening methods (i.e., universal Thai NIPT and contingent Thai NIPT) with the conventional tests as base case in all pregnant women.

The decision tree is an economic evaluation model suited for short-term diagnostic and screening decisions [8]. The tree consisted of $3 \mathrm{arms}$, i.e., conventional tests (i.e., either one of combined, triple, quadruple or full integrated test), Thai NIPT and contingent Thai NIPT (combination of conventional and Thai NIPT). More details of conventional test and Thai NIPT arms were explained in Figure 2. The tree started with all pregnant women who were counseled for performance of any of conventional tests or Thai NIPT. If they agreed to perform, the test results could be either positive or negative by estimating sensitivity and specificity of that prenatal screening test. For the positive test result, an amniocentesis was further offered to finalize the diagnosis of whether pregnant women had Down syndrome babies or not. For negative test result, the outcome of pregnancy was observed regarding the normal newborns, miscarriage and the abnormality of babies especially Down syndrome characteristics and then, a negative predictive value (NPV) was estimated. For pregnant women who declined performing screening tests, final outcomes were observed in the same way as the negative arm. The details of amniocentesis were presented in Figure 3. Commencing with acceptance of performing amniocentesis, the test results could be 3 possibilities; abortion from amniocentesis, true/false positive and true/false negative based on sensitivity and specificity of the tests. Denying the test would be either spontaneous abortion or live birth with Down syndrome or normal newborns.

\section{Parameter Uses}

Parameters in the model comprised of probabilities of occurrence of events, prenatal screening test performances including sensitivity, specificity, positive predictive value (PPV) and negative predictive value (NPV) and details of resource used as follows:

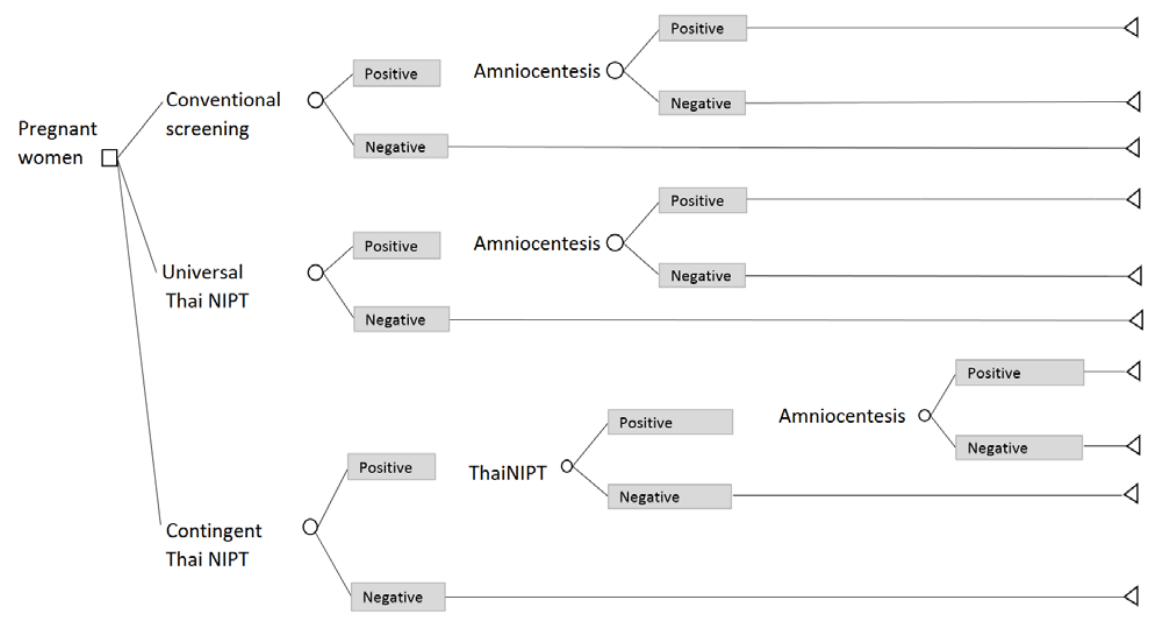

Figure 1: An overall decision tree of conventional tests, universal Thai NIPT and contingent Thai NIPT.

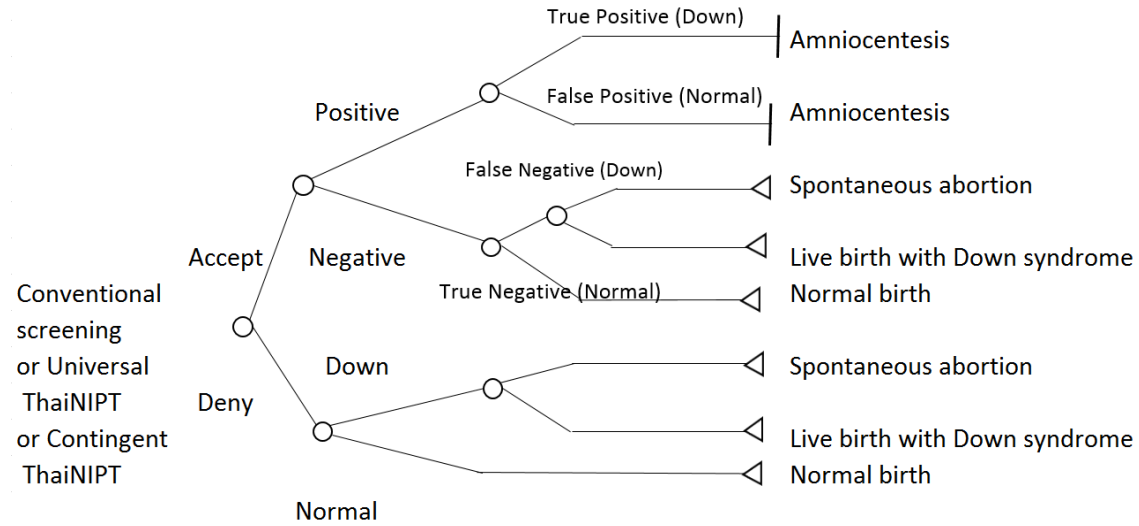

Figure 2: A decision tree of all possible results of conventional screening test/universal Thai NIPT/contingent Thai NIPT. 
Citation: Oraluck P, Boonsong O, Wasun C, Ammarin T, Panyu P (2017) Cost Benefit Analysis of Prenatal Screening Test with Thai NIPT (Thai NonInvasive Prenatal Test) for Down Syndrome in Developing Countries. Health Care Current Reviews 5: 207. doi: 10.4172/2375-4273.1000207

Page 3 of 7

\section{Probabilities of events}

Prevalence of Down syndrome in pregnant women, probability of abortion and test acceptance rate were retrieved from a study of cost-benefit analysis of prenatal screening and diagnosis for Down syndrome in Thailand in 2011 [3] (Table 1). The values ranged from 0 to 1 and they were adjusted by discount rate. With data from a total of 55,324 pregnant women between 1997 and 2016 from the Department of Obstetrics and Gynecology, Faculty of Medicine, Ramathibodi Hospital, Mahidol University, numbers of pregnant women aged younger than 35 years and at age of $\geq 35$ years were 41,050 and 14,274, respectively [9]. As a result, the ratio of pregnant women aged younger than $35 \geq 35$ years was 74.2:25.8.

\section{Performances of prenatal screening test}

Diagnostic performances of conventional tests, Thai NIPT and contingent Thai NIPT including sensitivity, specificity, PPV and NPV were retrieved from our previous study of Virology Laboratory and Center of Medical Genomics, Ramathibodi Hospital (Table 2) [9]. The ratio of combined per conventional tests in the simulation model for combined: triple: quadruple: Full integrated test was 26:20:24:30, respectively [10].

\section{Resource use}

Resource use of both costs and benefits in the study was considered based on societal perspective, which consisted of direct medical, direct non-medical, and indirect costs adjusted for discount rates with consumer price index to the year 2016 [11]. Direct medical cost of prenatal screening test, intentional abortion fee, and delivery fees were based on the price lists of Ramathibodi hospital (Table 3). As for our databases, the ratio of total numbers of caesarean section per numbers of normal delivery was at 60:40 [10]. Direct non-medical

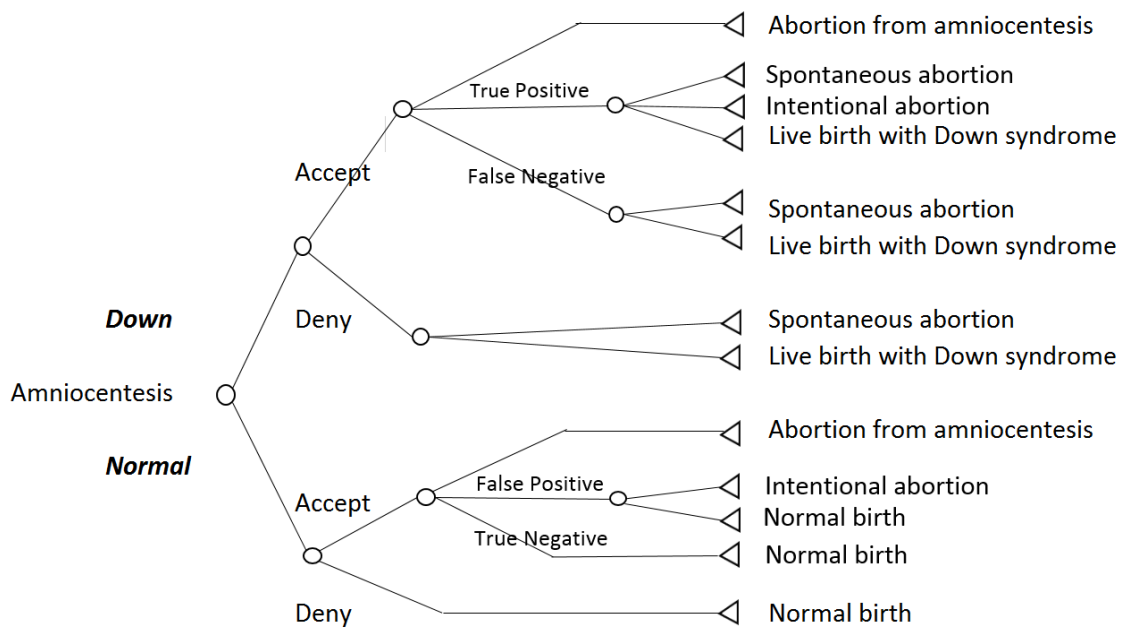

Figure 3: Amniocentesis's decision tree.

\begin{tabular}{|c|c|c|c|c|}
\hline Parameter & Type of distribution & Mean & Standard error & Reference \\
\hline Prevalence of pregnancy with Down syndrome in women aged $<35$ years & Beta & 0.0015 & 0.00005 & HITAP \\
\hline Prevalence of pregnancy with Down syndrome in women aged $\geq 35$ years & Beta & 0.0057 & 0.00024 & HITAP \\
\hline Probability of spontaneous abortion in Down syndrome pregnant women aged $<35$ years & Beta & 0.2600 & 0.00610 & HITAP \\
\hline Probability of spontaneous abortion in Down syndrome pregnant women aged $\geq 35$ years & Beta & 0.3500 & 0.00660 & HITAP \\
\hline Test acceptance rate in pregnant women aged $<35$ years & Beta & 0.9150 & 0.01050 & HITAP \\
\hline Test acceptance rate in pregnant women aged $\geq 35$ years & Beta & 0.9410 & 0.00880 & HITAP \\
\hline Amniocentesis acceptance rate in pregnant women aged $<35$ years & Beta & 0.9050 & 0.04480 & HITAP \\
\hline Amniocentesis acceptance rate in pregnant women aged $\geq 35$ years & Beta & 0.8570 & 0.03960 & HITAP \\
\hline Intentional abortion rate after positive test & Normal & 0.9200 & 0.00007 & HITAP \\
\hline Probability of abortion due to amniocentesis & Beta & 0.0065 & 0.00220 & HITAP \\
\hline
\end{tabular}

Table 1: Probability of occurrence of events as for various scenarios.

\begin{tabular}{|l|c|c|c|c|}
\hline \multicolumn{1}{|c|}{ Test (Cut-off risk) } & Sensitivity & Specificity & PPV & NPV \\
\hline Combined test (1:250) & 0.85 & 0.95 & 0.050 & 0.988 \\
\hline Triple test (1:250) & 0.81 & 0.93 & 0.040 \\
\hline Quadruple test (1:250) & 0.84 & 0.94 & 0.040 \\
\hline Serum integrated test (1:150) & 0.88 & 0.96 & 0.100 \\
\hline Full integrated test (1:150) & 0.90 & 0.97 & 0.100 \\
\hline Thai NIPT (trisomy 21) & 1.00 & 0.99 & 0.968 \\
\hline Amniocentesis & 0.99 & 0.99 & RAMA \\
\hline
\end{tabular}

Table 2: Describe diagnostic performances of conventional tests, universal Thai NIPT and contingent Thai NIPT. 
Citation: Oraluck P, Boonsong O, Wasun C, Ammarin T, Panyu P (2017) Cost Benefit Analysis of Prenatal Screening Test with Thai NIPT (Thai NonInvasive Prenatal Test) for Down Syndrome in Developing Countries. Health Care Current Reviews 5: 207. doi: 10.4172/2375-4273.1000207

Page 4 of 7

(i.e., caregiver's loss from traveling fee, food and accommodation) and indirect costs were based on Health Intervention and Technology Assessment Program (HITAP) study [3]. The indirect cost was productivity loss from intentional abortion of normal fetuses if the test was positive and spontaneous abortion from amniocentesis. Lifetime costs of Down syndrome, relevant treatments for complications, and child development costs were then considered as direct medical cost. Parents' informal care and income loss were included as direct nonmedical and indirect costs, respectively (Table 4).

\section{Cost-benefit analysis}

All costs have been converted to 2016 American \$ with the rate of 35.00 Thai Baht per US\$ [12]. Cost benefits of each of universal Thai NIPT and contingent Thai NIPT compared to conventional test as base case were calculated by using the following equations:

1) Difference of incremental benefit to incremental $\cos t=\Delta$ benefit $-\Delta$ cost

2) Ratio of incremental benefit to incremental $\cos t=\Delta$ benefit $/ \Delta$ cost

Where,

$\Delta$ benefit=difference of benefits from avoidance of Down syndrome children (an intervention compared to base case)

$\Delta$ cost $=$ difference of costs from performing the test (an intervention compared to base case).

In addition, number of live births with Down syndrome, spontaneous and intentional abortions, abortion from amniocentesis, and normal births were estimated from simulation with 800,000 replications [3]. The study also estimated the cost of Thai NIPT which would make the ratio of incremental benefit to incremental cost equal to one. Both cost and benefit were discounted with $3 \%$ inflation rate in the model.

\section{Sensitivity analysis}

Tornado diagram was plotted for one way sensitivity analysis by varying each parameter at a time with $95 \%$ confidence interval. Probabilistic sensitivity analysis was simulated in Microsoft Excel by using the Monte-Carlo method with number sampling 1,000 times according to each parameter's distribution.

\section{Results}

The analysis showed that as for the societal perspective, performing universal Thai NIPT and contingent Thai NIPT yielded differences of incremental benefit to incremental cost of $-4,472$ to $-3,784$ Thai Baht ( -127.77 to -108.11 US\$) and 396 to 1,085 (11.31 to 31.00 US\$) when each was compared to conventional tests. The ratio of incremental benefit to incremental cost was 0.03 to 0.14 for universal Thai NIPT and thus cost was saved for contingent Thai NIPT (Table 5).

Table 6 showed the expected number of events in each screening method estimated based on a total number of pregnant women/year of 800,000 . The expected numbers of live births with Down syndrome were 399, 277 and 403 cases for conventional Thai NIPT, universal Thai NIPT, and contingent Thai NIPT, respectively. The expected numbers of spontaneous and intentional abortions for these corresponding tests were 1,407. 1,432 and 1,257 cases; whereas expected numbers of abortions from amniocentesis were 233,15 and 9 cases, respectively.

A sensitivity analysis was performed by Tornado plot (Figure 4),

\begin{tabular}{|c|c|c|c|c|}
\hline Parameter & Type of distribution & Mean & Standard error & Reference \\
\hline \multicolumn{5}{|l|}{ Direct medical cost } \\
\hline Combined test & Gamma & 1,000 & 100 & RAMA \\
\hline Triple test & Gamma & 1,100 & 110 & RAMA \\
\hline Quadruple test & Gamma & 1,500 & 150 & RAMA \\
\hline Serum integrated test & Gamma & 400 & 40 & RAMA \\
\hline Full integrated test & Gamma & 2,400 & 240 & RAMA \\
\hline Thai NIPT (trisomy 21) & Gamma & 8,900 & 890 & RAMA \\
\hline Amniocentesis - chromosome & Gamma & 5,000 & 500 & RAMA \\
\hline Amniocentesis - consultation fee & Gamma & 756 & 75.6 & HITAP \\
\hline Intentional abortion fee & Gamma & 5,930 & 593 & RAMA \\
\hline Caesarean section & Gamma & 26,244 & 2,624 & RAMA \\
\hline Normal delivery & Gamma & 9,857 & 986 & RAMA \\
\hline \multicolumn{5}{|l|}{ Direct non-medical cost } \\
\hline Caregiver's loss & Gamma & 2,094 & 209 & HITAP \\
\hline \multicolumn{5}{|l|}{ Indirect cost } \\
\hline $\begin{array}{l}\text { Loss from abortion due to amniocentesis or intentional } \\
\text { abortion }\end{array}$ & Gamma & $1,265,823$ & 126,582 & HITAP \\
\hline
\end{tabular}

Table 3: Describe costs of prenatal screening tests, abortion and delivery fee (Thai Baht).

\begin{tabular}{|l|c|c|c|}
\hline \multicolumn{1}{|c|}{ Parameter } & Type of distribution & Mean & Standard error \\
\hline Direct medical cost & & & $1,000,678$ \\
\hline Lifetime cost & Gamma & & 100,068 \\
\hline Direct non-medical cost & Gamma & 780,235 & 78,024 \\
\hline Informal care & & & HITAP \\
\hline Indirect cost & Gamma & 860,061 & \\
\hline Income loss & HITAP & 86,006 \\
\hline
\end{tabular}

Table 4: Resource use - benefits from avoidance of Down syndrome babies (Thai Baht). 
Citation: Oraluck P, Boonsong O, Wasun C, Ammarin T, Panyu P (2017) Cost Benefit Analysis of Prenatal Screening Test with Thai NIPT (Thai NonInvasive Prenatal Test) for Down Syndrome in Developing Countries. Health Care Current Reviews 5: 207. doi: 10.4172/2375-4273.1000207

Page 5 of 7

\begin{tabular}{|c|c|c|c|c|}
\hline Various Down syndrome screening modalities & Cost & Benefit & $\Delta$ benefit $\Delta$ cost & $\Delta$ benefit $/ \Delta$ cost \\
\hline \multicolumn{5}{|l|}{ 1. Conventional test } \\
\hline - $\quad$ Combined test & 31,959 & 1,319 & & \\
\hline - $\quad$ Triple test & 32,330 & 1,563 & & \\
\hline - Quadruple test & 32,593 & 1,374 & & \\
\hline - $\quad$ Full integrated test & 32,897 & 1,044 & & \\
\hline $\begin{array}{l}\text { 2. Universal Thai NIPT: When comparing with the following } \\
\text { conventional test }\end{array}$ & 36,835 & 915 & & \\
\hline - $\quad$ Combined test & & & $-4,472$ & 0.08 \\
\hline - $\quad$ Triple test & & & $-3,858$ & 0.14 \\
\hline - Quadruple test & & & $-3,784$ & 0.11 \\
\hline - $\quad$ Full integrated test & & & $-3,809$ & 0.03 \\
\hline $\begin{array}{l}\text { 3. Contingent Thai NIPT: When comparing with the following } \\
\text { conventional test }\end{array}$ & 31,553 & 1,329 & & \\
\hline - $\quad$ Combined test & & & 396 & Cost saving \\
\hline - $\quad$ Triple test & & & 1,011 & Cost saving \\
\hline - Quadruple test & & & 1,085 & Cost saving \\
\hline - $\quad$ Full integrated test & & & 1,059 & Cost saving \\
\hline
\end{tabular}

Table 5: Cost benefit of each screening modalities (Thai Baht).

\begin{tabular}{|l|c|c|c|c|c|}
\hline $\begin{array}{l}\text { Various Down syndrome } \\
\text { screening modalities }\end{array}$ & \multicolumn{1}{|l|}{$\begin{array}{l}\text { No. of live birth with Down } \\
\text { syndrome }\end{array}$} & $\begin{array}{l}\text { No. of spontaneous and } \\
\text { intentional abortion }\end{array}$ & $\begin{array}{l}\text { No. of abortion from } \\
\text { amniocentesis }\end{array}$ \\
\hline 1. Conventional test & 399 & 1,407 & \\
\hline
\end{tabular}

Table 6: Number of events from various Down syndrome screening modalities.

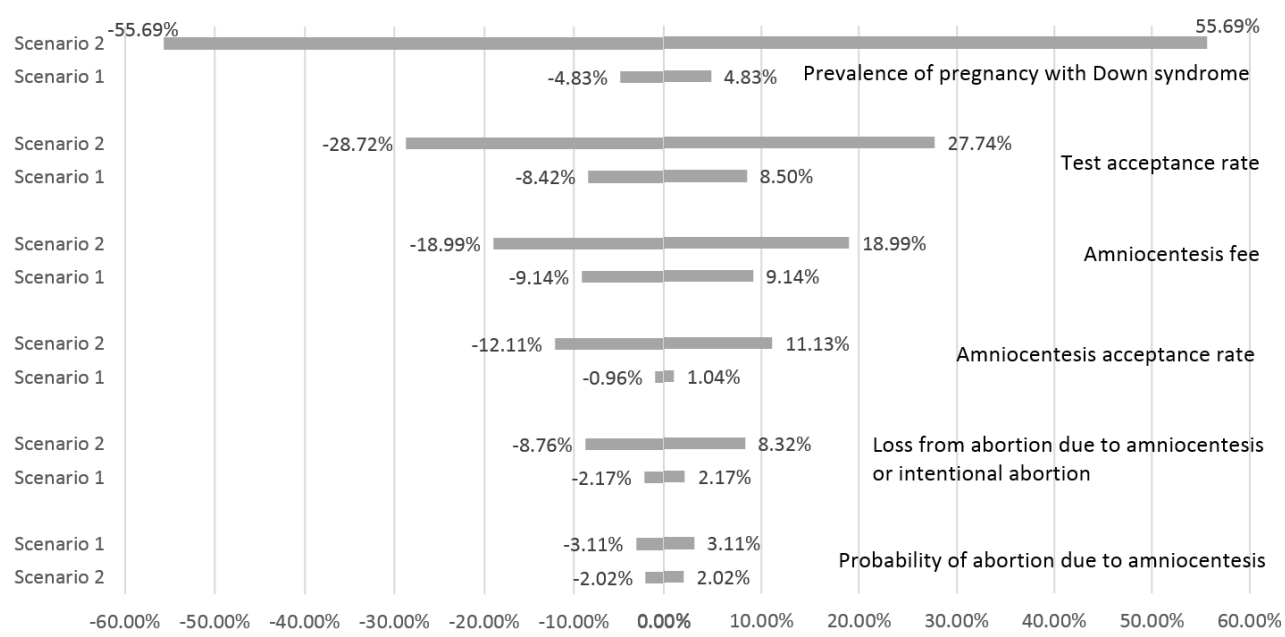

Figure 4: Tornado diagram.

which showed that the most sensitive parameter was prevalence of pregnancy with Down syndrome, followed by test acceptance rate in pregnant women and amniocentesis fee, respectively.

With probabilistic sensitivity analysis in Figure 5 and by decreasing test cost to reach ratio of incremental benefit to incremental cost at 1.00, the cost of Thai NIPT should be reduced to 4,047, 4,715, 4,795, 4,767 Thai baht $(115.63,134.71,137.00,136.20$ US\$) per test, when base case was combined with, triple, quadruple, and full integrated test, respectively.

\section{Discussion}

Health care costs vary considerably among countries. Focusing on the Down syndrome screening program in Thailand based on the Ramathibodi data, HITAP had showed the benefit of prenatal screening and amniocentesis for pregnant women of any age whose screening test was positive was the best value for money when compared with do nothing with the ratio of incremental benefit to incremental cost at 1.03:1.24 in 2011 [3]. After NIPT was introduced, ACOG (American College of Obstetricians and Gynecologists) statement in 


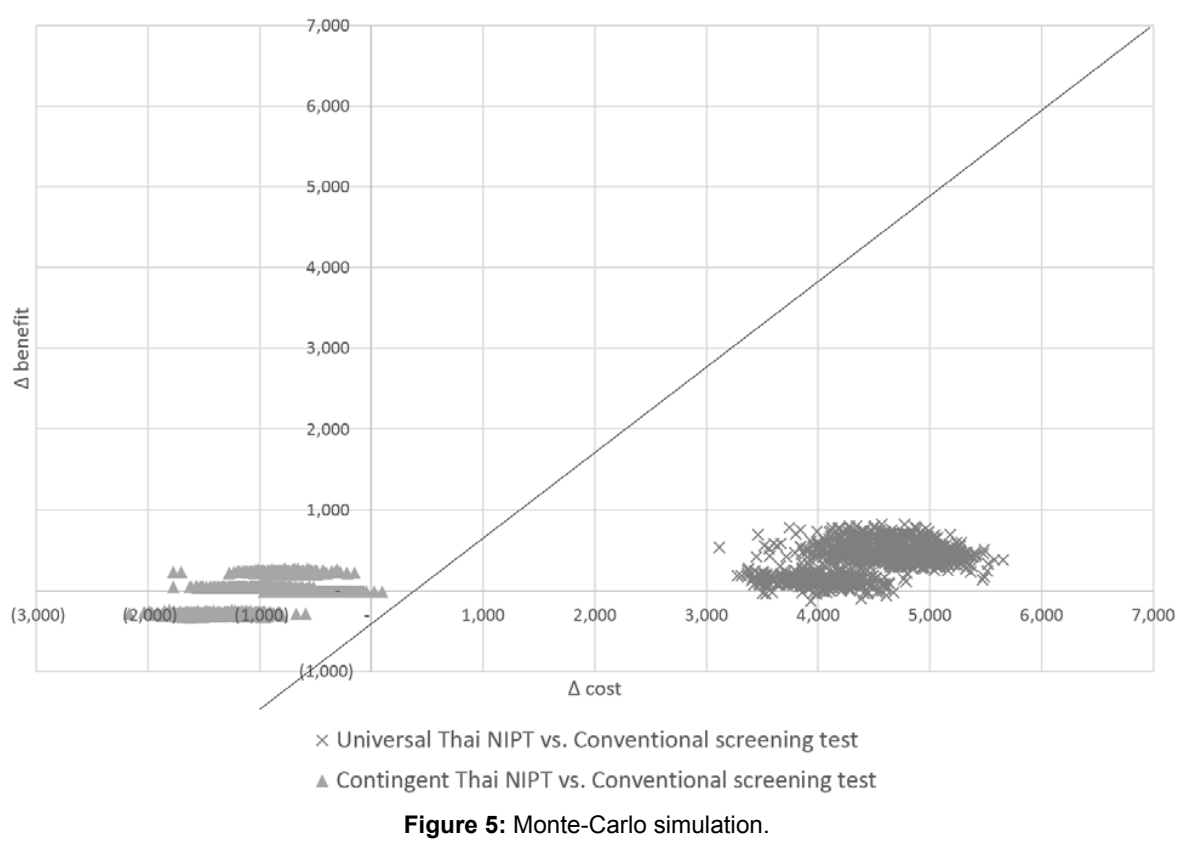

2012 supported NIPT only in the high risk pregnancy [13]. Shortly after, many studies validated the performance of NIPT in the general population $[14,15]$. This study was conducted to assess the cost benefit of prenatal screening test for Down syndrome using universal Thai NIPT and contingent Thai NIPT compared to conventional test as base case. The analysis showed that incremental benefit of universal Thai NIPT was lower than incremental cost. On the contrary, incremental benefit of contingent Thai NIPT was higher than incremental cost. Therefore, contingent Thai NIPT was cost saving.

Our findings were similar to two other studies which showed the benefit of contingent NIPT. A study by Gekas et al performed computer simulations comparing 8 screenings and found that contingent NIPT was the best choice with ICER (incremental cost effectiveness ratio) at Canadian \$ 3,815 per Down syndrome detected birth when compared to the second most CE (cost effective) strategy (serum integrated screening) [16]. Okun et al. also simulated 8 scenarios and found that contingent NIPT improved number of cases of Down syndrome detected prenatally and decreased cost per detected case [17].

A few studies later revealed the benefit of contingent test, but focused only on high risk pregnant women. Ayres et al conducted studies in Netherlands to estimate ICER (incremental cost effectiveness ratio) of implementing NIPT, as an optional secondary screening test for high risk pregnancies. They found that the ICER was about $k € 94$ per detected case when compared with conventional test alone in health care perspective, and about $\mathrm{k} € 460$ per detected case when NIPT was implemented alone as a primary screening test [18]. Tan $\mathrm{T}$ also found that offering contingent NIPT for high risk patients was cost effective when compared to conventional test with costs per patient of Singapore $\$ 407$ versus 342 , but not for performing NIPT with the cost per patient of Singapore \$1,011 [19].

Our study found that universal Thai NIPT would be cost effective as the first line of screening if the price/test was around 4,047 to 4,795 Thai Baht or US $\$ 115.63$ to 137.00 . In Australia, performing NIPT as first-line screening was not cost effective, because NIPT cost between AUD 575 and 900 in 2010 [20]. In America, for the general pregnancy population, screening by NIPT would be cost saving if NIPT cost was
US \$ 453 and below in 2014 [21]. However, with societal perspective, NIPT was a cost effective replacement for conventional screening test until the unit cost of NIPT was lower than US\$549 per test [22]. Although Thai NIPT cost was lower than other countries, it was still not cost effective if used as first-line screening, but it was cost saving when used as second-line after conventional screening test. Our study focused only on societal perspective. Principally, the screening policy depends on the economic perspective which should be considered upon three aspects: A societal perspective, government perspective and a payer perspective. Therefore, further study should be performed to include government as well as payer perspective. The cut-off risk optimization study of the contingent NIPT also needs to be undertaken in order to balance the test performance and the cost benefit.

\section{Conclusion}

Applying Thai NIPT as the first line of screening for Down syndrome might be cost beneficial if the price was around 4,047 to 4,795 Thai Baht or US\$ 115.63 to 137.00 per test. The contingent Down syndrome screening tests by offering the conventional tests first, then followed by Thai NIPT before performing the invasive screening test seems to be a cost beneficial alternative approach.

\section{References}

1. Sriwongpanich N (2008) Down syndrome child Bangkok: The agricultural cooperative federation of Thailand printing.

2. Jaruratanasirikul S, Kor-Anantakul O, Chowvichian M, Limpitikul W, et al (2017) A population-based study of prevalence of Down syndrome in Southern Thailand. World J Pediatr 13: 63-69.

3. Patanapesaj J, Tanmookayakul U, Teerawatananon Y (2011) Cost-benefit analysis of prenatal screening and diagnosis for Down syndrome in Thailand The graphico systems.

4. Taglauer ES, Wilkins-Haug L, Bianchi DW (2014) Review: Cell-free fetal DNA in the maternal circulation as an indication of placental health and disease. Placenta, pp: S64-S68.

5. Dondorp W, Wert G, Bombard Y, Bianchi DW, Bergmann C, et al. (2015) Noninvasive prenatal testing for aneuploidy and beyond: Challenges of responsible innovation in prenatal screening. Eur J Hum Genet 23: 1438-1450. 
Citation: Oraluck P, Boonsong O, Wasun C, Ammarin T, Panyu P (2017) Cost Benefit Analysis of Prenatal Screening Test with Thai NIPT (Thai NonInvasive Prenatal Test) for Down Syndrome in Developing Countries. Health Care Current Reviews 5: 207. doi: 10.4172/2375-4273.1000207

6. Cuckle H, Benn P, Pergament E (2015) Cell-free DNA screening for fetal aneuploidy as a clinical service. Clin Biochem 48: 932-941.

7. Panburana P, Wongkulab A (2016) Non-invasive prenatal test. Top sale marketing LTD, Bangkok, pp: 1-12.

8. Drummond MF, Sculpher MJ, Claxton K, Stoddart GL, Torrance GW (2015) Methods for the economic evaluation of health care programmes. Oxford University Press.

9. Chang $\mathrm{BCH}$, Chareonsirisuthigul $\mathrm{T}$, Janchompoo $\mathrm{P}$, Srichunrusami $\mathrm{C}$ Pasomsub E, et al. (2016) Setting up of first NIPT service laboratory in a Thailand hospital.

10. (2016) Data from Maternal Fetal Medicine Unit, Department of Obstetrics and Gynecology, Faculty of Medicine, Ramathibodi Hospital, Mahidol University, Bangkok, Thailand.

11. www.bot.or.th

12. www.bot.or.th/Thai/Statistics/FinancialMarkets/_layouts/Application/ ExchangeRate/ExchangeRate.aspx.

13. American College of Obstetricians and Gynecologists Committee on Genetics (2012) Committee Opinion No. 545: Noninvasive prenatal testing for fetal aneuploidy. Obstet Gynecol 120: 1532-1534.

14. Nicolaides KH, Syngelaki A, Ashoor G, Birdir C, Touzet G (2012) Noninvasive prenatal testing for fetal trimester in a routinely screened first-trimester population. Am J Obstet Gynecol 207: 374.e1-6.

15. Norton ME, Jacobsson B, Swamy GK, Laurent LC, Ranzini AC, et al. (2015)
Cell-free DNA analysis for non-invasive examination of trisomy. N Engl $\mathrm{J}$ Med 372: 1589-1597

16. Gekas J, Durand A, Bujold E, Vallée M, Forest JC, et al. (2011) Costeffectiveness and accuracy of prenatal Down syndrome screening strategies: Should the combined test continue to be widely used? Am J Obstet Gynecol 204: 175.

17. Okun N, Teitelbaum M, Huang T, Dewa CS, Hoch JS (2014) The price of performance: A cost and performance analysis of the implementation of cellfree fetal DNA testing for Down syndrome in Ontario, Canada. Prenat Diagn 34: 350-356.

18. Beulen L, Grutters J, Faas B, Feenstra I, Vugt J, Bekker M (2014) The consequences of implementing non-invasive prenatal testing in Dutch national health care: A cost-effectiveness analysis. Eur J Obstet Gynecol Reprod Biol 182: 53-61.

19. Tan $T$ (2015) Combined first trimester screen or non-invasive prenatal testing or both. Singapore Med J 56: 1-3.

20. Ayres A, Whitty J, Ellwood D (2014) A cost-effectiveness analysis comparing different strategies to implement noninvasive prenatal testing into a Down syndrome screening program. Aust N Z J Obstet Gynaecol 54: 412-417.

21. Fairbrother G, Burigo J, Sharon T, Song K (2016) Prenatal screening for feta aneuploidies with cell-free DNA in the general pregnancy population: A costeffectiveness analysis. Matern Fetal Neonatal Med 29: 1160-1164.

22. Walker BS, Jackson BR, LaGrave D, Ashwood ER, Schmidt RL (2015) A costeffectiveness analysis of cell free DNA as a replacement for serum screening for Down syndrome. Prenat Diagn 35: 440-446. 